\title{
Using the Anti-racism Digital Library and Thesaurus to Understand Information Access, Authority, Value and Privilege
}

by Anita Coleman, PhD

\begin{abstract}
The ACRL Framework for Information Literacy, specifically the six threshold concepts about information, mirrors the experiences of the author as a researcher studying the representation of anti-racism in bibliographic information systems. Anti-racism, in general, is a great concept to use when teaching information literacy and the paper discusses how antiracism information literacy can be taught and learned as part of theological and religious studies education. This paper was presented at the ATLA Annual Conference in 2017. Since the conference was in Atlanta, the article begins with two stories about the scholar DuBois who lived there, and which are also used to highlight information literacy concepts.
\end{abstract}

I am excited by the new ACRL Framework for Information Literacy (ACRL 2015, 2016). The six threshold concepts about information mirror my experiences as a researcher studying the representation of antiracism in bibliographic information systems and in developing the Anti-racism Digital Library and the International Anti-racism Thesaurus. Anti-racism, in general, is a great concept to use when teaching information literacy. Today, I will share how anti-racism information literacy can be taught and learned as part of theological and religious studies education. Since our conference is in Atlanta, I begin with two stories about the scholar W. E. B. Du Bois, who lived here.

\section{THE FIRST STORY}

"Under the leadership of W. E. B. Du Bois, Atlanta became a hub of early American sociology with rigorous empirical studies of black communities. One hundred years later, that history has been pushed to the sidelines” (Wright 2016). As Wright recounts, it was 1995 and he was a young graduate student at the University of Chicago feeling uncomfortable, sitting alone in the library, recalling his childhood reading of Du Bois' The Philadelphia Negro in his grandparents' home: “[I]f the Chicago School of Sociology studies were conducted in the 1920's [sic] and the Pittsburgh survey was conducted in 1907, why are they considered the earliest and most important urban sociological investigations? Why is W. E. B. Du Bois' The Philadelphia Negro, published in 1899, not considered the first urban sociological investigation or even acknowledged by sociology instructors or in sociology textbooks?” He began to review the existing literature, "singularly focused... on proving why Du Bois' Philadelphia Negro, not the Pittsburgh survey, was the first urban sociological study conducted in the United States" (Wright 2016). Using the tools of his discipline, Wright showed how Du Bois' work was co-opted and marginalized. His findings are detailed in the book The First American School of Sociology: W.E.B. Du Bois and the Atlanta Sociological Laboratory.

\section{THE SECOND STORY}

A year earlier, in 2015, The Author Denied: W.E.B. Du Bois and the Birth of Modern Sociology was published by the University of California Press. A book excerpt reads thus:

This paper was originally read at the Seventy-first Atla Annual conference, held in Atlanta, Georgia, from June 14-17, 2017. 
In this groundbreaking book, Aldon D. Morris's ambition is truly monumental: to help rewrite the history of sociology and to acknowledge the primacy of W. E. B. Du Bois' work in the founding of the discipline. Calling into question the prevailing narrative of how sociology developed, Morris, a scholar of social movements, probes the way in which the history of the discipline has traditionally given credit to Robert E. Park at the University of Chicago, who worked with the conservative black leader Booker T. Washington to render Du Bois invisible. Morris uncovers the seminal theoretical work of Du Bois in developing a "scientific" sociology and examines how the leading scholars of the day disparaged and ignored Du Bois' work. Morris delivers a wholly new narrative of American intellectual and social history that places one of America's key intellectuals, W. E. B. Du Bois, at its center. ... The Scholar Denied is a must-read for anyone interested in American history, racial inequality, and the academy (Morris 2015, inside cover).

\section{OUR INTELLECTUAL TRADITIONS AND EPISTEMIC RACISM}

What we see from these two stories is that there is a 'black' sociological tradition that grew up alongside 'white' sociology and the mainstream did not recognize the existence of two parallel sociologies. Library systems failed, too. I searched WorldCat for The Philadelphia Negro. As an example, the 1996 edition of the book, bound with another, is described thus: "The Philadelphia Negro is the first, and perhaps still the finest, example of engaged sociological scholarship-the kind of work that, in contemplating social reality, helps to change it” (De Gruyer 2020).

In the USA, 'Black' studies have been legitimated as departments in our institutions of higher learning and also as subject headings in information infrastructures such as the Library of Congress Subject Headings (LCSH), e.g., the subject heading for 'Black Theology.' The anti-racism scholar Alana Lentin (2017) notes that "due to 'epistemic racism' in Australia, disciplines such as sociology or cultural studies do not have [a similar] institutionally legitimated black tradition" (127). However, this does not mean that epistemic racism is absent in the USA. It is worthwhile to revisit the meaning of epistemology in the light of anti-racism. Epistemology is a philosophic theory of the method or basis of human knowledge, exploring questions such as how knowledge is acquired and what assumptions are made in the historical development of knowledge. "This area of inquiry is critical to understanding racism because the dominance of western knowledge systems produces and promotes beliefs about racialized culture as inferior to western culture" (Reading 2013). Three traditions: Greco-Roman culture, Christianity, and the scientific method are privileged while other ways of knowing and seeing are deemed inferior and marginalized. This is epistemic racism. So there is an important point to note here. All of us, and it doesn't matter what color our skin is-as products and willing participants of Western education-are complicit in the practice of epistemic and other forms of racism as well as the processes of racialization.

\section{'ANTI-RACISM' IN THE LCSH}

In 2016, in "Theology, Race, and Libraries," my first paper presented at the Atla Annual conference in Long Beach, I discussed how the Library of Congress Subject Headings (LCSH) contribute to institutional and systemic racism (Coleman 2016). There is only one LCSH for 'Anti-racism' and almost no relationship list. In the paper, I highlighted how theology is complicit in the creation of the construct of race and various expressions of racism such as the doctrines of discovery, slavery, Apartheid, Nazism, as well as in the efforts to defeat it with anti-racism such as La Resistance, anti-slavery/abolition, civil rights and racial reconciliation movements. 'Race relations' we saw was authorized and by 2016 had literally hundreds of other related headings, including 'Racism' which was suggested as a replacement for 'Race Discrimination' but remains together (Berman 1973). Even though the old LCSH of the 'Race Problem' once known as the 'Negro Problem' is no longer used, 'race' problems are much more visible than the solutions of 'Antiracism.' For example, a book on 'Anti-racism education' had been assigned "Race Relations - Study and Teaching” and the behaviors and beliefs that are an integral part of 'Anti-racism' are not always assigned this subject heading. Instead they are given 'Racism' or similar subject headings.

The Anti-racism Digital Library and International Anti-racism Thesaurus (ADL) was begun to build a clearinghouse of anti-racism resources as well as to develop and use the language of anti-racism in or- 
der to mitigate the unintended structural racism bias of library information infrastructures, such as the LCSH. Discovering and naming the 'Anti-racism' vocabulary will make solutions to the 'race' problem better understood. Assigning 'anti-racism' subject headings will improve intellectual access and alleviate many other bias problems such as faulty generalization, inappropriate terminology, the privileging of universalism, white as normative, ghettoization, treating as exceptions, omission, being procrustean, and hegemony over diversity in order to achieve efficiency, and more.

\section{'ANTI-RACISM' AND INFORMATION LITERACY}

In this paper, I highlight some of the ADL developments. In the process, I show ADL use for theological libraries along with the new ACRL Information Literacy (IL) framework. Not just for students but also for ourselves for informational professional growth, research, and the promotion of our own critical thinking about information access, authority, value, and privilege.

As I mentioned earlier, I am excited by the new ACRL IL framework. In curating the ADL, I find the six threshold concepts described in the new framework playing out over and over again: 1) Authority is constructed and contextual; 2) Information creation as a process; 3) Information has value; 4) Research as inquiry; 5) Scholarship as conversation; and 6) Searching as strategic exploration.

Anti-racism is an excellent topic for use with the development of these new literacy skills.

Example: Biblical word study of race: Examine one of the key texts that is often used in conversations about race, Revelation 7:9 (ESV): After this I looked, and behold, a great multitude that no one could number, from every nation, from all tribes and peoples and languages, standing before the throne and before the Lamb, clothed in white robes, with palm branches in their hands ... The underlined words, when translated correctly from the original language, reveal no race. Nation $=e$ thnos Tribe $=$ phyle People $=$ laos Language $=$ glossa .

That's a quick example. Students can be assigned Bible word studies of the term "race" at levels suitable for both beginners and experts. Experts can be asked to trace the origins of the concept of 'race' in primary and secondary sources beyond the Bible while beginners are guided through a limited and preselected list of texts. This is an invaluable way to teach and learn new information literacy skills along with the religious subject. Appendix 1 is an anti-racist writing exercise, a small example of how we can begin to dismantle racism by changing the language.

Racialization is another concept/topic that can be used to teach information literacy as well as in the professional development of librarians of all kinds engaged in tasks as varied as cataloging and instruction.

As I describe the ADL structure, I hope that other concepts and ideas will come to your mind.

\section{THE ANTI-RACISM DIGITAL LIBRARY THESAURUS AND DESCRIPTORS FOR PEOPLE GROUPS}

The ADL is dedicated to the victims of the 2015 Charleston AME church shooting. I mostly work with local community and church groups. Hence its structure is simple. There are Collections with items (resources), About, Glossary, Thesaurus (pages), and a form to Contribute an item, which can be an information resource such as confession, prayer, story, etc.

Critical race theory and findings from anti-racism education drive the research and development of the library and thesaurus. For idealists in critical race theory, language matters. A rich and actively growing vocabulary for racism-e.g. micro-aggressions-without corresponding anti-racism solutions, only continues to perpetuate racism. Hence developing the language of anti-racism and understanding it becomes preeminent, including the descriptors for people groups. Color labels such as blacks, whites, and people of color are a product of thinking purely in terms of a social myth and have become a technique for increasing political power. They build group identity and cross-cultural solidarity, but findings show 
that grouping people as whites, blacks, and people of color also eternalizes discriminatory codes that give pre-eminence to skin color over other meaningful markers. Additionally, they cause despair, disunity, continuing bias. They don't dismantle racism and whether or not they will help increase economic and educational equality, bring racial equity, and achieve racial justice remains in the balance. In contrast, anti-racism work done by facilitating critical information literacy has the potential for easing inequities. In addition to teaching anti-racism information literacy, catalogers and metadata creators can participate and contribute by changing the existing vocabularies for people groups.

The Library of Congress Subject Headings (LCSH), as we all know, are often used to describe people as 1) intended audiences (e.g. Children), 2) creators and contributors (e.g. Book editors), and subjects (e.g. Asian Americans). In 2013, the Library of Congress began to separate the three purposes and create a new, controlled vocabulary for the first two only. The first edition of the Library of Congress Demographic Groups Terms (LCDGT), published last year, contains 827 authorized terms. In the LCDGT, "Whites" is not an authorized term for intended audiences or creators and contributors. "White supremacists" is. You will also find the term "Blacks," but you won't find "People of color." Since authorized terms are selected using the principle of literary warrant this means that only the most common terms used in content (books, journal articles) become preferred headings. That "Whites" did not make it is something to which those interested in anti-racism should pay attention. It reinforces related research findings from over a decade and it offers catalogers, indexers, metadata managers and similar librarians a rare opportunity as well.

"Antiracism calls white people to a negative task: critiquing racism and white privilege and acting against them. It is difficult to persuade white people to join a cause in which their identity is deconstructed without a positive rebuilding" (Williams and Schoon 2007, 286). From their qualitative study of students in an evangelical, midwestern college, Paris and Schoon concluded that "rather than offering a new white identity derived from antiracist philosophy (such as "antiracist," "white ally" or "post-white"), antiracist teachers may tap other aspects of identity as motivators for action against racism. Motivating people to work against racism based upon a particular group's deepest identity (be it religious, political, geographical, and so forth), may provide more positive and lasting identity attachments” (Williams and Schoon 2007, 300). Studies investigating how race, religion and politics intertwine have reiterated this. However, minority status/identity politics is the driving force for Blacks. Blacks, with or without faith, are more committed to racial group membership while whites are more tied to denominational affiliation (Shelton and Emerson 2012).

Privilege continues to be a hallmark characteristic of whiteness. From a global or psychological point of view, though, there are many different kinds of privilege besides white skin privilege such as male, Christian, heterosexual, ability, and social class. Discrimination based on social class is more common since a large number of people in the world are poor. Similarly, most of the world is Christian; males are favored in a number of cultures; heterosexuality tends to be the norm as also ability versus disability. Skin color privilege, though, is unique because it has been used to perpetuate the construction of one human race into two at least, if not many others. In addition, the constructs of "whiteness" and "blackness" are communicated through culture, education, and maintained through politics. Whiteness especially often builds, transcends and assimilates light skin color privilege: Rwanda's 1994 genocide, India's caste system, Brazil's embranquecimento (palmitagem). It is no wonder, then, 'White Supremacists' gets conflated to Whites and why some people don't want to and/or cannot identify as White!

It is difficult enough to call anybody-of any color-to anti-racism given the universal preference for lighter skin (colorism) and the heterogeneity and complexity of racism. When we put people into color boxes to describe them, we lose. The time has come to put aside the color labels 'Whites' and 'People of Color.' I have mixed feelings about the term Blacks-it has been legitimated; blackness and black identity, like whiteness, is constructed but appears to be needed to offset bias (e.g., from religious and literary traditions that equate light with good and dark or black with evil). However, we can encourage the media and in our own in-house reports start to use ethnicity/indigeneity, ancestry, culture, education, 
class, faith/religion, occupation/field of activity, national/regional origin and location, language, and others. The 'Poor Whites' subject heading has an equivalent 'Poor Blacks' LCSH subject heading. 'Working class whites' didn't have an equivalent 'Working class blacks' but had two headings ('Working class' and 'Blacks'); yet, we know that intersectionality is one of the biggest challenges in achieving justice be it racial or economic.

'Whites,' however, continues to be used in WorldCat as a subject heading. The figure below shows the total first and then the yearly number of books that have received a Library of Congress Subject Heading of 'Whites' and 'Blacks' from 2010 to 2017. As you can see, there are more books with 'Blacks'; the norm is White and hence, often not explicitly assigned.

The ADL Thesaurus seeks to describe anti-racism in all its fullness in order to fuel the scorching of race and ignite cooperation for justice and peace by discovering and crafting a new vocabulary for describing complex humanity. The goal for the thesaurus is to be useful in everyday language as well as for assigning subject headings in library catalogs and indexing databases. Thus, the Glossary is one of the first steps towards developing a DictionaryThesaurus. Terms and phrases, when completed, will describe

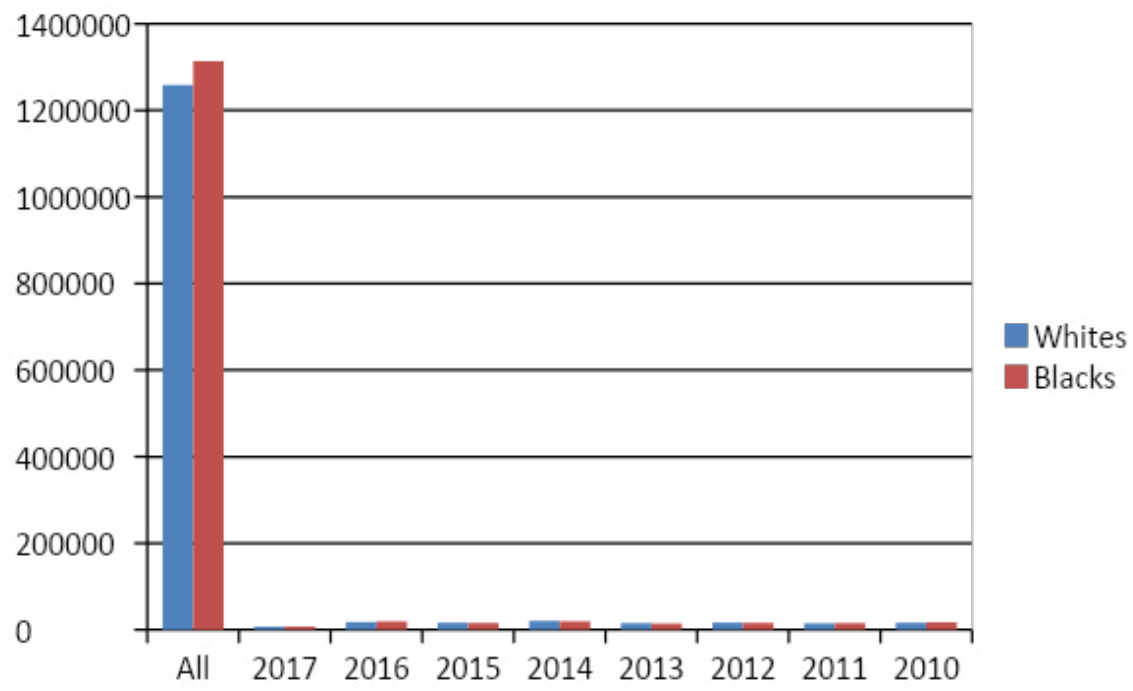

Figure 1: Books Assigned LCSH 'Whites' and 'Blacks' by Year anti-racism concepts, policies, strategies, and movements, not just in the U.S.A. but in the global arena as well. Terms for people groups and genre/form will come from two other sources: Library of Congress Group Demographic Terms (2015, 2017) and Atla Genre Forms for Religious Works/Library of Congress Genre Form Terms (2015, 2016).

There is a rare opportunity here for catalogers, indexers, and similar professionals to help develop the vocabulary for anti-racism by contributing new subject headings when you note anti-racist behaviors and practices. If you're not exactly sure how this can be done, it will become clearer by the end of the paper after we have discussed the ADL Glossary, Collections and some anti-racism concepts such as Linguicism, Bystander Anti-racism, Tolerance, and Inclusion. Appendix 2 lists the expected learning outcomes. Appendix 3 provides a preliminary framework of the Anti-racism vocabulary and highlights the terms and concepts that are already in the LCSH but almost never used with the LCSH Anti-racism. Appendix 4 outlines the six IL threshold concepts and some examples for increasing, learning, and teaching what I call "anti-racism information literacy.”

\section{ANTI-RACISM DIGITAL LIBRARY GLOSSARY}

The Anti-racism Digital Library Glossary brings together words from diverse disciplines. Works by antiracism scholars, inclusive style guides from anti-racist organizations, and Critical Race Theory (CRT) by Ricardo and Stefancic are major sources of the Glossary. The inclusion terms for people are still under investigation and the Glossary is updated continuously. CRT terms are given in boldface black, including some of its basic tenets. Additionally, the scriptures of diverse faith traditions, selective texts from Christian liberation theologies, scholarship about anti-racism, comparative religion, human rights, multicultural education, and positive peace are included. My ideas about categorization, notably frames, ideal- 
ized cognitive models, metaphors, bias, and prototypes are influenced by George Lakoff's (1987) Women, Fire and Dangerous Things: What Categories Reveal About the Mind.

I share two examples, one from an emerging discipline and another, Nuance Theory, from an established sociology. These can be tailored to teach/learn any of the IL threshold concepts such as "authority is constructed," "scholarship as conversation," or even "research as inquiry."

Linguicism/Languagism-language discrimination-refers to Linguistic Human Rights, a growing area of study which combines the study of language as a central dimension of ethnicity, along with national and international law. There are many types of language discrimination:

- Linguistic Imperialism

- Accent Prejudice and Dialect Prejudice

- Drawl

- English-Only Movement

- Language Myth

- Language Planning

- Multilingualism

- Native Speakerism

- Prestige

Nuance Theory is the view that one may determine the essential qualities of a group such as women, and that differences from that essential core may be treated as slight variations or shades of difference. Recently there has been some backlash. A paper about nuance theory that was presented at the American Sociological Conference was quickly downloaded over 12,000 times! Comments on the site are instructive about how academic knowledge is contested and constructed: "Social science is an oxymoron - and, a deception. At best, it should be called social studies. But, the truth is it's just another bogus 'discipline' designed to indoctrinate people with humanist ideology as substitute for critical thinking." Similar conversations exist in the religious studies and theology arenas. For example, ADL has brought together many resources from the mainline denominations in specific kinds of collections to teach and learn anti-racism IL.

\section{ANTI-RACISM DIGITAL LIBRARY: COLLECTIONS}

The motivation behind Collections is to bring together information resources created by and for diverse people, groups and projects that are adapting anti-racism to help and to build inclusive and caring communities. Findings from anti-racism research are used to name the collections. There are two kinds of Collections. One showcases specific groups or individuals. The second offers research and resources that help construct new language for anti-racism.

\section{Examples-}

Presbyterian Women Collection and a recent resource: Bias Free Guidelines. A Presbyterian Women/ Horizons style sheet addendum of guidelines for writing with inclusive and socially just language.

The Intercultural Community PC(USA) Collection and recent resources: Well Chosen Words! Inclusive Language With Reference to the People of God and Expansive Language With Reference to God, a PC(USA) tri-fold brochure, and Facing Racism-policy, guides, and more of the PC(USA)'s 2016 antiracism initiative. 
Collections such as Anti-racist Identity, Racial Imagination, American Identity, Christian Imagination, Intersectional Invisibility, Reclaiming Ourselves, and American Myths offer new language for fueling the human imagination with concepts and categories that describe essential humanity beyond 'color labels' based on skin color and phenotypic variations.

\section{WHAT IS IN AN ADL COLLECTION? HOW CAN IT BE USED TO TEACH IL?}

Each Collection contains items, i.e., information resources, in seven genres. As an example, consider the Christian Imagination. It currently has a total of thirteen resources in the following genres:

1) Genre: Research article/study - Resource: Jenell William Paris and Kristin Schoon, "Antiracism, Pedagogy, and the Development of Affirmative White Identities Among Evangelical College Students."

2) Genre: Bible Studies - Resource: On Scripture - The Bible, "Jesus is woke and we should be too."

3) Genre: Books or Book Reviews - Resource: Jonathan Tran, "The New Black Theology: Retrieving Ancient Sources to Challenge Racism.”

4) Genre: Exercises/Open Educational Resources - Resource: Anita Coleman, "Building an Inclusive, Caring Community: Unveiling Perception and the Christian Identity,” Anti-racism Digital Library.

5) Genre: Church Confessions/Policy - Resource: "Love Thy Neighbor as Thyself."

6) Genre: Key Bible Verses - Resource: Anita Coleman, "Discipleship and Diversity in the Bible.”

7) Genre: Stories, narratives, art - Resource: “Women’s March 2017 (Protest Signs).”

Appendix 3 provides a preliminary framework of the Anti-racism vocabulary for the thesaurus. Two specific types of anti-racism concepts listed there-a behavior and belief-are described below briefly in terms of their usefulness and potential for teaching IL.

\section{BYSTANDER ANTI-RACISM}

Bystander anti-racism is an anti-racism behavior. It is a topic that can be used to develop information literacy skills as it has gained popularity in recent years. The aim of bystander anti-racism is to shift social norms toward intolerance of everyday racism. It appears to displace race and challenge racism. The problem with bystander anti-racism is that it constructs racist acts as 'deviant,' i.e. casual racism. It is not engaging with the deeper injustices or halting white dominance or supremacy. Furthermore, bystander anti-racism is seen as overreaction if a member of the same ethnic group who is the racism target engages in it. So it tends to reinforce or center whiteness in anti-racism and continues the property interest in whiteness; i.e., white skin and white identity are economically and otherwise valuable.

\section{TOLERANCE AND UNLEARNING IT FOR INCLUSION AND/AS ANTI-RACISM}

Tolerance, like Inclusion, is an anti-racism belief/value. However, many resist it and ask: "Who wants to be tolerated? I want to be accepted, respected, fully included.” King and Springwood (2001) present findings and discuss the intersections of signification, power, and race, specifically the use of Native American mascots in college sports. Researchers found that it is not enough to teach tolerance, "what might best be described as pluralistic and superficial understandings of difference that celebrate diversity and too often dovetail with dominant interests and ideologies"; this is what CRT calls interest convergence, when racial justice is pursued only when it benefits the dominant group. 


\section{INCREASING ANTI-RACISM INFORMATION LITERACY (AIL)}

I found the new ACRL IL framework to be an indicator of the way in which I progressed from being a novice or beginner in 'anti-racism' to more of an 'expert.' Information Authority, Access, Value, and Privilege took on a greater depth of meaning in light of anti-racism. My area of library specialization is intellectual access, specifically how can metadata, subject headings, thesauri and similar tools improve access to content. I was aware of the racial divide statistics about digital information and information technology access and use just as I knew about the biased and prejudiced subject headings. But I hadn't realized how much of this is structural, built into our systems because of epistemic racism. Similarly, I was aware of privilege, but learning about white privilege in the church, for example, led me to consider how information privilege exists. Appendix 4 outlines some examples for teaching and learning antiracism information literacy.

\section{CONCLUSION}

1) Anti-racism is a great topic for developing critical information literacy skills, be it that of the student or the teacher-librarian. Categorization is a fundamental human activity and we all use categories and tend to discriminate whether we are aware of it or not. Part of teaching intellectual access means we become aware of our own implicit bias as well as learning to recognize bias in our information infrastructures such as the library catalog, reference databases, thesauri, and subject headings.

2) Anti-racism Information Literacy means teaching about the process of racialization as well as epistemic racism - students are equipped with the tools to identify the social construction of race or races and to recognize, engage and challenge the reconstructions of racial identities, ideologies and hierarchies. Like people, issues too are racialized (welfare, domestic violence, housing, immigration). Racialization is a fluid process.

3) Anti-racist teaching is about more than recognizing difference or even stereotypes. Anti-racism using the new ACRL framework in theology and religious studies will develop pedagogy and incite professional development that directs attention toward the disruption of white supremacy as a structured social system so that inequities can be corrected.

4) Racism and racialization shape and are shaped by schools and thus librarians are in a unique position to challenge white normativity as well as address systemic bias.

5) Anti-racism Information Literacy articulates, makes visible, and teaches how different communities have been racialized differently-Euro-Americans, Native Americans, African Americans, Asian Americans, Hispanics, and now MENA (US Census 2020).

6) Anti-racist information literacy concerns itself with the sites of pedagogy that matter to those it seeks to hail in the classroom.

7) Anti-racist teaching must join the key conflicts of the day by having a strong presence with peace and justice work.

8) Appendices 1 through 4 provide a simple exercise, the learning outcomes from this paper, the antiracism vocabulary that has been developed, and some examples for increasing anti-racism information literacy.

\section{WORKS CITED}

Association of College \& Research Libraries. 2015, 2016. "Framework for Information Literacy for Higher Education.” Accessed September 22, 2017.

Anti-Racism Digital Library. n.d. “Anti-Racism Digital Library.” Accessed 18 October, 2019. 
Berman, Sanford. 1973. Prejudices and Antipathies: A Tract on the LC Subject Heads Concerning People. Jefferson, NC: McFarland.

Coleman, Anita. 2016. “Theology, Race, and Libraries.” Atla Summary of Proceedings 70: 65-74.

DeGruyter. n.d. “The Philadelphia Negro.” Accessed December 6, 2019.

Du Bois, W. E. B. (1996). The Philadelphia Negro. Together with a special report on domestic service by Isabel Eaton. Philadelphia: University of Pennsylvania Press.

King, C. Richard and Charles Fruehling Springwood. 2001. Beyond the Cheers: Race as Spectacle in College Sports. Albany: State University of New York Press.

Lakoff, George. 1987. Women, Fire and Other Dangerous Things: What Categories Reveal About the Mind. Chicago: University of Chicago Press.

Lentin, Alana. 2017. “(Not) Doing Race: 'Casual Racism', 'Bystander Antiracism’ and 'Ordinariness' in Australian Racism Studies.” In Critical Reflections on Migration, 'Race' and Multiculturalism: Australia in a Global Context, edited by Martina Boese and Vince Marotta, 125-42. London: Routledge.

Library of Congress. n.d. Library of Congress Subject Headings. Accessed September 22, 2017.

—. 2015, 2017 "Library of Congress Demographic Group Terms.” Accessed September 22, 2017. . 2015, 2016. “Genre / Form Headings at the Library of Congress.” Accessed December 6, 2019.

Morris, Aldon D. 2015. The Scholar Denied: W.E.B. DuBois and the Birth of Modern Sociology. Oakland: University of California Press.

Paris, Jennell William and Kristin Schoon. 2007. "Antiracism, Pedagogy, and the Development of Affirmative White Identities among Evangelical College Students." Christian Scholar's Review 36, no. 3: 285-301.

Reading, Charlotte. 2013. “Understanding Racism.” Accessed December 6, 2019.

Shelton, Jason and Michael Emerson. 2012. "Reconciling the Race Problem: Identity Politics and the Gulf between Black and White Protestants.” In Blacks and Whites in Christian America: How Racial Discrimination Shapes Religious Convictions, 168-98. New York: New York University Press.

Wright, Earl II. 2016. “The Work and Legacy of W.E.B. Du Bois.” Accessed 16 October, 2019.

—. 2016. The First American School of Sociology: W.E.B. Du Bois and the Atlanta Sociological Laboratory. Burlington, VT: Ashgate Publishing. 


\section{APPENDIX 1: BUILDING AN ANTI-RACIST VOCABULARY EXERCISE}

The following sentences employ racist language and values. Please identify and underline the racist terminology then rewrite the sentence using antiracist language. Example:

82 of the students in SF public schools are minority students.

Antiracist Rewrite:

82 of the students in SF public schools are students of color.

What else can we use instead of students of color?

Some Possible Answers: students from historically marginalized groups; students from the subordinate groups

Challenge: Librarians, Catalogers, Indexers, can you suggest some alternate terms from the current literature or diverse library contexts?

\section{APPENDIX 2: LEARNING OUTCOMES}

Become informed about ways to collaborate with the Anti-racism Digital Library/Thesaurus

- About, Glossary, Thesaurus Pages, Collections, Contribute

Increase understanding of anti-racism information literacy for racial equity and justice

- Concepts: Anti-racism, Bystander anti-racism; Epistemic racism

Be inspired to think about ways to use $A D L / T$ resources in research and assignment design

- Examples: “Anti-racism” and "Racialization” as threshold concepts rather than 'Race' or 'Racism'; Biblical word studies of 'race'

\section{APPENDIX 3: ANTI-RACISM VOCABULARY: A PRELIMINARY FRAMEWORK FOR THE FACETED THESAURUS}

Core concept: Anti-racism

\section{Preliminary Facets (are given in boldface type below)}

Beliefs/Values (e.g. Community, Diversity, Equality, Equity, Faith, Hospitality, Human Rights, Humanism, Inclusion, Justice, Non-violence, Peace, Spirituality, Tolerance, Unity)

Actions - Practices - Strategies (e.g. Advocacy, Anti-racism training, Anti-violence training, Awareness training, Community building, Conflict resolution, Cultural action, Cultural democracy, Cultural transformation, Educational events, Dialogue/discussions, Organizational change, Youth activities, Skill-building training; Political participation; Identity politics)

Movements (e.g., Civil Rights movement; Interfaith movement)

Policies (affirmative action; includes laws, too, e.g., Universal Declaration of Human Rights, Genetic Information Non-discrimination Act of 2008 (GINA) USA)

Organizations (e.g., UN; Catalyst Project; Anti-racism for collective liberation; Stand Up for Racial Justice)

People (e.g., groups such as African Americans) 
Periods (e.g., modern, 1492 onwards, etc.)

Space (e.g., United States)

Concepts of anti-racism: Anti-racist education; Bystander anti-racism; Integrative anti-racism; Tolerance; Inclusivity, Reparation

Closely related concepts: Diversity, Racial categories/taxonomies/typologies, Racial equity, Racial healing, Cultural racism, Bio-racism; Restorative justice; Competitive advantage; Innovation

Related concepts: Race; Racism; Racialization, Multiculturalism (narrow term); Social justice (broad term)

Domains/Disciplines: Cultural/Ethnic studies, Education, International Indigenous studies, Positive peace, Theology

Peripheral areas: Biology, Cultural anthropology, Genomics, Psychology, Sociology

\section{Anti-racist policies (examples):}

- inclusivity

- neutrality or "colorblindness";

- cooperative (not competitive) workplace environment;

- affirmative action initiatives and scholarships directed towards increasing diversity;

- multi-culturalism / pluralism / solidarity

Anti-racist actions (some examples of how people are actively practicing anti-racism):

- Practicing Cultural Humility - LCSH: Cultural humility

- Acknowledging White Privilege - LCSH: White Privilege

- Interfaith Dialog - LCSH: Interfaith dialog

- Christian Witnessing - LCSH: Witness bearing (Christianity)

- Faithful Rhetoric - LCSH: Faith; Rhetoric; Civic Engagement

- Standing in Solidarity - LCSH: Solidarity

- Original Purpose/Divine Calling (for everybody not just clergy) - LCSH: Vocation

Anti-racist movements (examples):

- Anti-apartheid movements

- Civil Rights Movement

- Indigenous or Self-development of People movement

- Interfaith movement

- Spirituality movements

- Sustainability movements (e.g., campus sustainability)

- Crowdsourced syllabi (campus activism movements)

- Black Lives Matter

- Academic Reparation (current)

- Moral Mondays

- Second Poor People's Campaign 


\section{APPENDIX 4: ACRL FRAMEWORK FOR INFORMATION LITERACY — SIX THRESHOLD CONCEPTS AND SOME EX- AMPLES FOR INCREASING/LEARNING/TEACHING ANTI-RACISM AND INFORMATION LITERACY}

1) Authority Is Constructed and Contextual - e.g., Find two or more anti-racist theologians, scholars, or activists whose views are markedly different; identify some of the conflicts that exist in current anti-racism activism or research.

2) Information Creation as a Process - e.g., Trace the development of the concept of 'anti-racism' in the context of the church; explore related concepts such as restorative justice.

3) Information Has Value - Ownership of liturgies and sermons - who owns a pastor's intellectual work? Use a key anti-racist church figure such as Martin Luther King, Jr.

4) Research as Inquiry - What is integrative anti-racism and what are its implications for us as religious studies scholars? What is the academic reparation movement in theology/religious studies and what is its impact?

5) Scholarship as Conversation - Trace the origins of the Belhar Confession (or other anti-racist confession/doctrine) and discuss how it came to pass, accepted by professional clergy and laity.

6) Searching as Strategic Exploration - e.g., Intellectual access (LCSH, LCDGT, etc.) 